\title{
O SIGNIFICADO DA USINA HIDRELÉTRICA Cachoeira do Emboque, em Minas Gerais, PARA SEUS ATINGIDOS ${ }^{a}$
}

\section{The significance of the Chachoeira do Emboque dam in Minas GERAIS STATE FOR THE AFFECTED PEOPLE}

\author{
Narayana de Deus Nogueira Bregagnoli
}

\begin{abstract}
Resumo O presente estudo procurou compreender como comunidades afetadas pela construção de uma Usina Hidrelétrica (UHE) percebem as modificações que esse empreendimento causa em suas vidas, após a implantação da barragem. Os conflitos evidenciados no decorrer do processo de negociações com a empresa proponente resultaram em descontentamento por parte daqueles que teriam que enfrentar mudanças significativas em suas vidas. Dessa forma, o objetivo geral do estudo foi a análise do significado da barragem para seus atingidos. A perspectiva qualitativa foi desenvolvida tendo como suporte teórico discussões acerca dos impactos relacionados à implantação de projetos hidrelétricos, além de reflexões sobre as categorias espaço, lugar e território. Os resultados da pesquisa indicam que grande parte dos atingidos se sente insatisfeita com as mudanças ocorridas em seus meios e modos de vida, razão pela qual se conclui que o sentimento de desenraizamento e desterritorialização se faz presente na comunidade.
\end{abstract}

Palavras-chave atingidos; barragens; impactos.

Abstract The present study analyzes families in communities affected by a Dam, and how they notice the modifications in their lives after the building of the dam. The conflicts during the negotiation process with the company which sponsored the dam project, were marked by division among the affected people. These facts resulted in dissatisfaction for those who would face significant changes in their lives. In this context the main objective of this study was to understand the meaning of the dam

a Este artigo foi produzido com base em Dissertação de Mestrado apresentada à Universidade Federal de Viçosa, em 2007.

b Professora do Ifsuldeminas e mestre em Extensão Rural pela UFV. 
among those who had been affected by this project. Using a qualitative perspective, the research was developed using theories on the negative impacts caused by the dams, as well as reflections based on several analytical categories, in particular: space, place and territory. The results of the research indicate that most of those affected are dissatisfied with the changes that took place in their way of life. We conclude that most of those interviewed expressed a feeling of loss of identity with their place and their past.

Keywords affected; dams; impacts.

\section{INTRODUÇÃo}

Sabe-se que é inquestionável afirmar que a sociedade necessita de energia para sua sobrevivência no mundo atual, seja nas indústrias, em seus diversos usos comercias, nas residências, no auxílio ao cultivo de determinados produtos agrícolas, na criação de animais, entre outros usos, o que nos torna seres completamente dependentes dessa tecnologia, utilizando-a de diversas maneiras, como é o caso da eletricidade.

Como forma de adaptação à vida urbana que segue uma lógica capitalista e que, por sua vez, pretende atender às necessidades do ser humano, ao longo dos tempos, diversas formas de uso de energia foram desenvolvidas para nossa utilização, seja ela por meio de queima de combustíveis, como os gases e óleos naturais, da utilização dos ventos ou pelas quedas d’água. Todas são formas eficientes de se obter eletricidade, umas mais, outras menos, porém sua obtenção por meio das quedas d'água passou a ser mais utilizada e se denomina energia hidrelétrica.

As usinas hidrelétricas são exemplos do desenvolvimento dessas tecnologias e, em países onde os recursos hídricos favorecem o aproveitamento do potencial hidroenergético, como no caso do Brasil, elas se tornam matrizes do setor energético, uma vez que a ótica capitalista do país faz prevalecer os interesses mercadológicos, já que quem faz maior parte do uso dessa energia são as indústrias, principalmente no setor de alumínio, e não a população em geral. Ou seja, a produção de energia elétrica vem sendo tratada como de uso coletivo, mas sua apropriação acontece de forma privada, o que gera o uso desigual dos recursos naturais do país.

Contudo, considerando os estudos já realizados, tornou-se público e notório o fato de que a formação do reservatório e a construção da barragem implicam sérios impactos sociais, como a remoção de famílias e o desaparecimento de comunidades, com suas práticas culturais, além de impactos ambientais que se 
acumulam, como o desaparecimento de espécies animais e vegetais ameaçadas de extinção, paisagens naturais e sistemas ecológicos.

Apesar de inúmeras críticas e da produção de pesquisas que comprovam os efeitos negativos ocasionados pela construção das barragens, o investimento nesse setor não para de crescer e tornou-se tão grande em todo o mundo que, de acordo com dados da Comissão Mundial de Barragens (apud VAINER, 200o), mais de 800.000 barragens já foram construídas no planeta, sendo que 45 mil são de grande porte. Tais empreendimentos provocam o deslocamento de cerca de quatro milhões de pessoas a cada ano, além de causar grande impacto na biodiversidade.

Em razão do vasto tamanho do território brasileiro e da quantidade de rios passíveis de aproveitamento hidroenergético, afirma-se que mais de 2.00o barragens já foram construídas no país e mais de um milhão de famílias de agricultores rurais e populações indígenas foram deslocadas, desde a década de 1970. Esse panorama começou a ser criado no período do regime militar, a partir da criação da Eletrobrás e das empresas estatais vinculadas ao Ministério das Minas e Energia. No entanto, essa política gerou "não apenas hidreletricidade, mas também efeitos sociais perversos" (SigAud, 1994, p.1).

A partir desse momento, em todo o mundo, importantes agências internacionais de financiamento, como o Banco Mundial, passaram a criar grandes linhas de crédito para investir na construção de tais empreendimentos. Contudo, definidas a partir de critérios "técnicos" e sob a pressão de grandes grupos empresariais interessados apenas em viabilizar a realização dos lucrativos empreendimentos com hidrelétricas, principalmente as de grande porte, essas políticas, públicas ou privadas, não têm levado muito a sério as implicações sociais que a inundação dessas áreas pode trazer às populações que ali residem (Sigaud, 1994, p. 3).

Percebe-se, então, que as hidrelétricas são exemplo do processo de modernização advindo do regime capitalista, e, por isso, sua implementação traz consigo o discurso de "melhoria na qualidade de vida, progresso e desenvolvimento regional" (CARvalho, 2005, p. 5).

Dessa forma, buscou-se, por meio deste trabalho, analisar e compreender se a melhoria e o progresso realmente ocorrem nos locais onde são construídas as usinas hidrelétricas, e, para tal, fora escolhida a UHE Cachoeira do Emboque, em decorrência de três aspectos relevantes: o tempo significativo de construção da usina (mais de dez anos); por ser uma barragem construída ao final da década de 1990, sem realização de audiência pública (no mesmo período em que vários projetos de barragem, em locais próximos, como: Pilar, Cachoeira Grande, Cacho- 
eira da Providência, tiveram Audiências Públicas ${ }^{1}$ ); e pela ausência de estudos sobre esse caso, em contraste com os citados anteriormente.

Entre os objetivos da pesquisa, encontram-se: a descrição e análise das percepções das famílias atingidas pela UHE Cachoeira do Emboque, que passaram pelo processo de deslocamento e realocação, problematizando o referido processo; a realidade social vivida no passado e no presente; suas percepções sobre seus meios e modos de vida, antes e depois da barragem, no sentido de apreender o significado por elas atribuído ao empreendimento, bem como as perdas e os eventuais ganhos para essas famílias. Dessa forma, procurou-se compreender, sob a ótica da população afetada pelo empreendimento, quais os efeitos sociais, culturais, materiais e ambientais a construção dessa UHE gerou na comunidade.

Para dar continuidade à temática aqui abordada, considera-se importante mencionar rapidamente a definição de uma palavra que será apresentada durante todo o texto, o termo "atingido". A Comissão Mundial de Barragens considera que os atingidos são formados por "categorias de agricultores sem terra, ocupantes, arrendatários, parceiros, populações indígenas, bem como as famílias dos agricultores, proprietários ou não” (RотнмаN, 1996, p. 131). No entanto, a partir das lutas dos atingidos por barragens, para ampliar a definição de atingido, a ElETrosul se viu obrigada a reconhecer os grupos que não haviam sido incluídos inicialmente, bem como a redefinir "os fatores que afetariam as pessoas: não apenas a água, mas também as linhas de transmissão, alojamento dos operários de construção e o terreno do comando" (Rothman, 1996, p. 131). A abordagem conceitual de atingido para órgãos internacionais como a International Financial Corporation (IFC), o Banco Mundial e a Comissão Mundial de Barragens é considerada mais abrangente, não a restringindo aos afetados diretamente pela água. Essa inovação conceitual ocorreu a partir da incorporação da noção de "pessoas economicamente deslocadas”. Dentro desse viés, passam a ser incluídos os pescadores que perdem ou têm sua pesca consideravelmente reduzida, agricultores que deixam de ter acesso à agricultura de vazante, aqueles que se encontram na condição de deslocados econômicos, estando, portanto, todos inseridos na categoria de atingido.

Na questão das construções das barragens, seguindo a ótica capitalista, formada por grupos que se atentam somente aos interesses econômicos e defendem os empreendimentos hidrelétricos, alega-se que eles contribuem para o desenvol-

1 O artigo de Rothman (2001, p. 319) conclui que "a falta de acesso à audiência pública, no caso Emboque, foi, sem dúvida, fator significativo nos resultados desfavoráveis para a comunidade atingida”. 
vimento nacional e local. Por outro lado, os críticos apontam os efeitos negativos que projetos de tal porte podem ocasionar, como afirma Martins (1993, p. 61-63):

Não se trata de introduzir nada na vida de ninguém. Aqui se trata de projetos econômicos de envergadura, como hidrelétricas, rodovias, planos de colonização, de grande impacto social e ambiental, mas que não tem por destinatárias as populações locais. Seu pressuposto é o da remoção dessas populações. [...] não se trata de introduzir nada na vida dessas populações, mas de tirar-lhes o que tem de vital para sua sobrevivência, não só econômica: terras e territórios, meios e condições de existência material, social, cultural e política. É como se elas não existissem ou, existindo, não tivessem direito ao reconhecimento de sua humanidade.

De acordo com o autor, quando o "estranho" (os projetos de desenvolvimento) surge na vida dessas pessoas, eles chegam com um discurso completamente sedutor, ao propor às pessoas um grande progresso, modernidade, oportunidades de emprego, uma falsa ascensão social, dadas as indenizações, oportunidades de ir para a cidade e de consumo, fatores que influenciam em uma decisão inicial a favor do "progresso", em um momento em que as populações identificam apenas as benesses da construção. No que se refere aos jovens locais, a chegada da barragem ainda pode significar a possibilidade de se mudar para a cidade, de dar continuidade aos seus estudos, a busca por melhores condições financeiras e de trabalho e, por conseguinte, de acesso a bens de consumo e "à cultura moderna" (cinema, shoppings, bares, roupas, etc.), apontados na pesquisa de Medeiros (2002, p. 3).

Como consequência, nesse momento em que a população já se encontra fragilizada pelas dúvidas e incertezas de seus destinos, embebedadas pelas esperanças no progresso ali proposto, desune-se, não se mobiliza, em uma situação em que seria necessária a formação de uma identidade de resistência ao projeto, o qual certamente acarretará impactos positivos e negativos aos seus meios e modos de vida.

Alguns autores, como Santos (2002), afirmam que esse discurso desenvolvimentista, proposto pelas empresas, tem como prioridade a dimensão econômica desses empreendimentos, e não a social:

Quando nos dizem que as hidrelétricas vêm trazer, para um país ou para uma região, a esperança de salvação da economia, da integração no mundo, a segu- 
rança do progresso, tudo isso são símbolos que nos permitem aceitar a racionalidade do objeto que, na realidade, ao contrário, pode exatamente vir destroçar a nossa relação com a natureza e impor relações desiguais (SANTOS, 2002, p. 173).

O próprio Banco Mundial, que foi um dos maiores financiadores de hidrelétricas, desde a década de 1970, e, portanto, corresponsável pelo deslocamento de milhares de famílias em todo o mundo, reconhece que, nos projetos de construção de barragens, quase sempre se inicia um processo de empobrecimento, muitas vezes representado pela perda da terra, do trabalho, da habitação, pela marginalização das famílias atingidas, pelo aumento da mortalidade, pelas dificuldades de acesso à alimentação e pela desarticulação dos atingidos (CERNEA; MCDOWELl, 2000).

Os referidos autores ainda afirmam que "a expropriação da terra retira o principal fundamento sobre o qual são construídos o sistema produtivo das pessoas, suas atividades comerciais e seu meio de vida. Essa é a principal forma de descapitalização e empobrecimento de pessoas deslocadas [...]" (CERNEA; MCDOWELL, 2000, p. 23).

Ludwig (2003, p. 3) já afirma que isso ocorre por eles se imporem sobre a "valorização da natureza e da vida, subjugando os potenciais ecológicos, destruindo formas de organização social, desterritorializando identidades, enterrando saberes práticos e desarraigando a cultura de seus referentes locais".

A Comissão Mundial de Barragens ${ }^{2}$ assegura que, além de serem deslocados pela perda de suas terras (desterritorialização), as compensações financeiras pagas aos atingidos não são suficientes para que possam restabelecer seus meios de vida em outro lugar. Os reassentamentos, quando existem, muitas vezes possuem terras de baixa qualidade ou improdutivas.

As áreas de reassentamentos são sempre selecionadas sem uma referência ou estudos sobre a viabilidade econômica das mesmas, bem como uma consulta sobre as preferências das pessoas deslocadas. Estes são geralmente forçados a reassentar em locais com áreas ambientais degradadas no entorno da represa.

2 Fruto dessa articulação e por pressão dos movimentos de atingidos por barragens de todo o mundo, ainda no ano de 1997, é criada, na Suíça, a Comissão Mundial de Barragens (CMB), ligada ao Banco Mundial e com a participação de representantes de ONGs, Movimentos de Atingidos, empresas construtoras de barragens, entidades de financiamento e governos. A CMB teve o objetivo de levantar e propor soluções para os problemas causados pelas construtoras de barragens no nível mundial, bem como propor alternativas. Desse debate, que durou aproximadamente três anos, resultou o relatório final da CMB, que mostra os problemas causados pelas barragens e aponta um novo modelo para tomada de decisões (fonte: <http://www.mabnacional.org.br/ menu/historia.html, acessado em 14/05/2013>). 
Assim, as terras perdem rapidamente suas capacidades produtivas para dar suporte às populações reassentadas (WCD apud VAINER, 2000, p. 107).

Estudos etnográficos (Scherer-Warren et al., 1990) também destacam as consequências negativas de empreendimentos hidrelétricos sobre os atingidos, uma vez que essas populações perdem todo o investimento feito por uma ou várias gerações na propriedade rural em que, muitas vezes, nasceram seus antepassados e descendentes, bem como a tranquilidade do espaço vivido e construído socialmente, o sentido de "lugar", seus valores e a identidade individual e/ou social. Além disso, também são destacadas as perdas sociais e simbólicas, ou seja, a ruptura das relações de vizinhança, parentesco, comunidade, assim como as perdas de bens culturais, tais como igreja, cemitério, escola, costumes e tradições.

O impacto, a longo prazo, sobre as famílias atingidas pelas barragens pode revelar as rearticulações sociais e ambientais que ali se instalam. Nesse jogo de interpretações dos processos de mudança desencadeados pela construção de barragens, quais seriam as versões dos sentimentos e significados desse movimento, pela população atingida?

\section{IDENTIFICAÇÃO E DELIMITAÇÃO DA ÁREA DO ESTUDO}

A unidade de análise do referido estudo foi constituída pelas famílias atingidas pela UHE do Emboque, que foi construída entre os municípios de Raul Soares e Abre Campo, pertencentes à Zona da Mata Mineira, apontados na Figura 1 a seguir.

A referida barragem foi construída no Rio Matipó, pertencente à Bacia Hidrográfica do Rio Doce3, como apresentado na Figura 2.

As famílias diretamente atingidas pelo empreendimento foram as residentes das comunidades rurais de Córrego da Praia e Valão (no distrito de Granada, pertencente ao município de Abre Campo) e de São Lourenço de Baixo (no distrito de Bicuíba, pertencente ao município de Raul Soares), apontados na Figura 3, a seguir.

3 Dados retirados da Resolução 121, de 2004, da AneEl. Disponível em:<http://www.aneel.gov. br/cedoc/rea2004121.pdf>. 


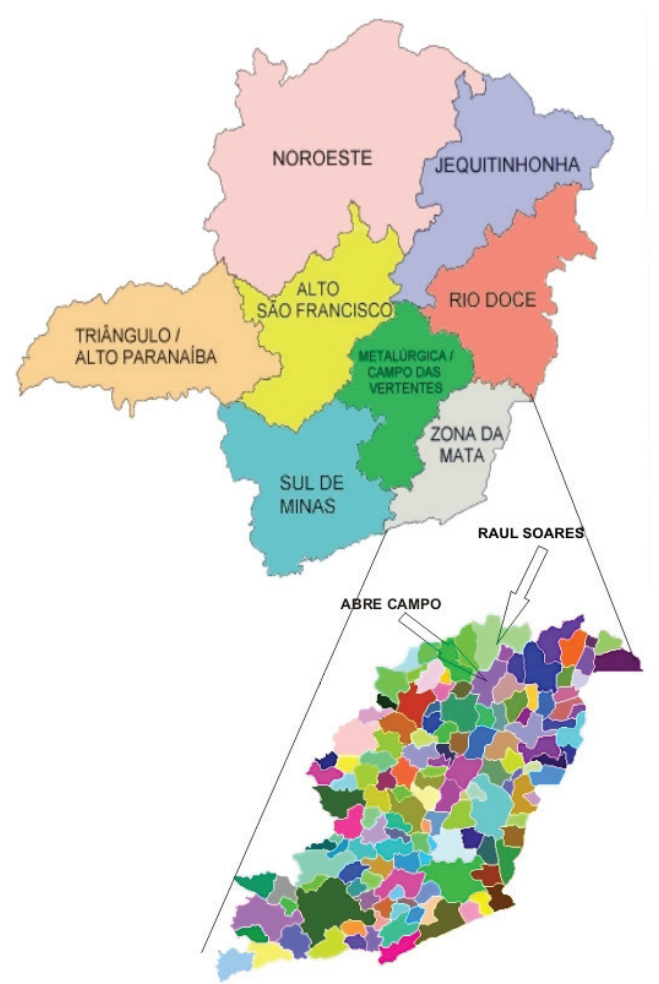

Figura 1. Mapa de Minas Gerais e da Zona da Mata Mineira, em destaque os municípios de Abre Campo e Raul Soares. Fonte: <www.geominas.mg.gov.br>.

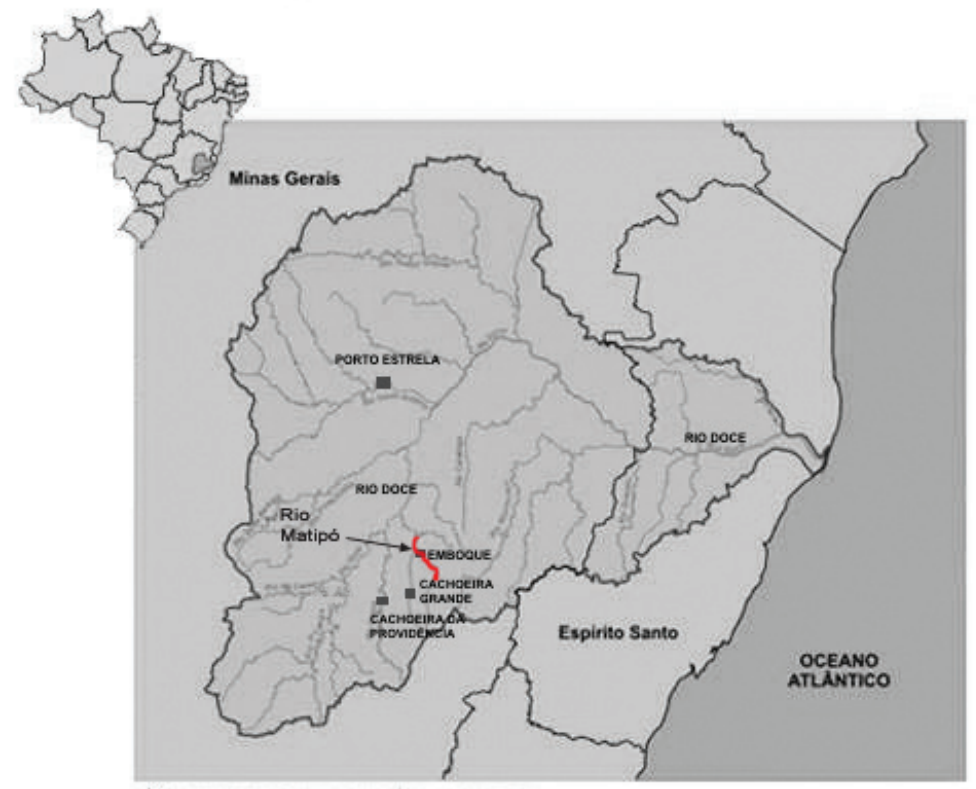

Figura 2. Em destaque o Rio Matipó, pertencente à Bacia do Rio Doce, MG, com algumas das principais barragens da região, inclusive a do Emboque. É importante enfatizar que as PCHs Cachoeira da Providência e Cachoeira Grande ainda são projetos não aprovados. Fonte: <www.simge.mg.gov.br/.../mapa_bacia_small.gif>. 


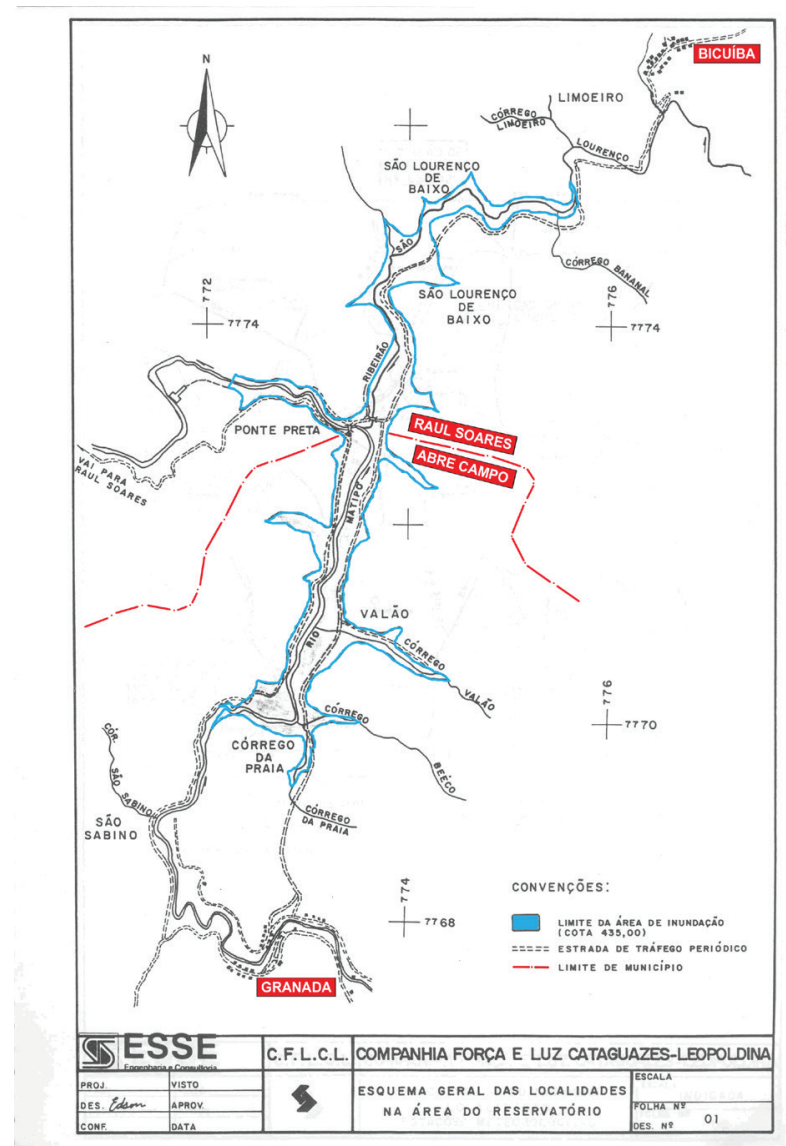

Figura 3. Mapa da região, anterior à construção da UHE do Emboque, elaborado pela ESSE Engenharia e Consultoria. Fonte: RImA UHE Cachoeira do Emboque.

\section{SOBRE OS MÉTODOS E TÉCNICAS DA PESQUISA}

O delineamento de uma pesquisa implica a escolha de determinada perspectiva analítica. No presente caso, preocupou-se com a natureza qualitativa das informações e do processo de construção de dados, pois, dessa forma, torna-se possível aprofundar "no mundo dos significados das ações e relações humanas, um lado não perceptível e não captável em equações, médias e estatísticas” (MinaYo, 1997, p. 22). Assim, a investigação do sentido ou do significado das qualidades dos dados construídos é que se transforma na verdadeira busca para o entendimento das percepções da população estudada.

De modo geral, esta pesquisa trabalhou com a obtenção de descrições obtidas pela pesquisadora, por meio de análise documental e de entrevistas.

Assim, a primeira etapa consistiu na identificação das famílias atingidas. Inicialmente, foi realizada consulta às listas e aos documentos dos cadastros dos 
atingidos encontrados no RimA ${ }^{4}$ e no acervo do Movimento dos Atingidos por Barragens (MAB). Identificadas as famílias, inclusive os nomes de cada membro, buscaram-se informações sobre o tipo de relação do atingido com a terra, se proprietário, meeiro ou arrendatário, o tipo de produção, o padrão fundiário das propriedades e informações sobre as negociações entre atingidos e empreendedor.

A segunda etapa da pesquisa foi marcada pelo trabalho de campo, em que se passou à coleta de dados e informações sobre a situação atual da população atingida. Os trabalhos de campo foram realizados em três etapas, e em todas elas contou-se com o apoio de um informante inicial, apresentado por um membro do Núcleo de Assistência às Comunidades Atingidas por Barragens (NACAB)5.

Dessa forma, foram entrevistadas trinta e duas famílias, sendo dezoito residentes nas comunidades rurais do distrito de Granada (que pertence ao município de Abre Campo), e onze no distrito de Bicuíba (pertencente ao município de Raul Soares). Ainda foram entrevistadas mais três famílias de atingidos que, mesmo vendendo suas propriedades e se mudando para outra região (duas do município de Caputira e uma do município de Manhuaçu), foi possível localizá-los por possuírem laços de parentesco ou apadrinhamento com famílias que permaneceram no local.

Para realizar essa construção de dados, utilizou-se a modalidade de entrevistas semiestruturadas, com perguntas previamente formuladas, porém sempre deixando a possibilidade de se encaminharem outras perguntas ou comentários que não estavam previamente formulados no questionário. Pretendia-se gravar as entrevistas, porém vinte e seis dessas famílias não concordaram em fazê-lo. Argumentaram que não se sentiam à vontade com o uso do aparelho ou se mostraram desconfiadas e receosas de que as gravações fossem utilizadas para outros fins. Afirmaram tal fato ter acontecido anteriormente. Eles se diziam cansados de ser alvo de pesquisas, muitas delas realizadas por outras instituições de ensino, principalmente de cursos particulares de Direito da região próxima a Raul Soares. Dessa forma, a pesquisadora conduziu as entrevistas anotando as respostas à mão, pois não autorizaram a gravação, o que foi realizado apenas com seis famílias. Por esse motivo, serão apresentadas falas fiéis ao que foi dito, das que foram gravadas, conservando a linguagem e o vocabulário do falante, e, em outros momentos, serão apresentadas falas assim como foram registradas nas anotações da pesquisadora.

4 Alguns dados sobre o processo de licenciamento (EIA/RIMA) para a implantação da UHE Emboque foram registrados e arquivados pelo professor pesquisador Franklin Daniel Rothman, que trabalha com a temática das barragens tanto em projetos de pesquisa como de extensão.

5 Ele é atual advogado da ONG e assessorou a população atingida por intermédio do NACAB, enquanto projeto de extensão da UFV, no ano de 1997. 
Para garantir uma variedade representativa da população de atingidos, bem como a diversidade de pontos de vista, foram entrevistados, nas duas primeiras etapas: agricultores em geral (homens e/ou mulheres), proprietários rurais que moravam na área da UHE; ex-proprietários; não proprietários, incluindo meeiros, ex-meeiros e trabalhadores rurais, assim como suas esposas e filhos, quando possível.

Dessa forma, ao final da construção de dados, foram entrevistadas trinta e duas famílias, que continham, em média, de dois a quatro membros em cada residência. Desses entrevistados, dezoito famílias pertenciam ao distrito de Granada (quinze proprietários, um arrendatário e dois meeiros), sendo que quatro famílias entrevistadas possuíam parentesco; três outras famílias também pertencentes a outro ramo familiar e as demais famílias de ramos independentes. Também foram entrevistadas onze famílias do distrito de Bicuíba (sete proprietários, sendo dois com propriedade ainda não legalizada, e quatro meeiros ${ }^{6}$ ).

Todas as famílias que contribuíram para a construção dos dados do presente trabalho se declararam como pequenos produtores rurais, com a agricultura alicerçada no trabalho familiar. As propriedades também foram declaradas com tamanhos entre um e vinte hectares, sendo que, atualmente, a produção declarada ${ }^{7}$ está voltada para a subsistência.

\section{A TRANSFORMAÇÃO DE UMA POPULAÇÃO ATINGIDA POR UMA BARRAGEM EM MINAS GERAIS}

A partir do entrelaçamento das teorias e pesquisas que trabalham com a temática aqui abordada e dentro do contexto das privatizações do setor energético e da nova concessão de produção energética em Minas Gerais, surge a construção da Usina Hidrelétrica (UHE) Cachoeira do Emboque, situada ente os municípios de Raul Soares e Abre Campo, pertencentes à Zona da Mata Mineira.

A construção dessa barragem afetou diretamente a vida de noventa e quatro famílias que eram constituídas por um povoado tipicamente ribeirinho, composto por famílias de pequenos agricultores rurais, sendo eles proprietários e não proprietários que, em sua maioria, eram de baixa renda e possuíam baixa escolaridade. A dinâmica econômica da região era essencialmente rural, pautando-se na agricultura de base familiar, além da prática da pesca ao longo do rio.

6 As quatro famílias de meeiros são do mesmo ramo familiar.

7 As produções declaradas foram: milho, feijão, cana-de-açúcar, leite e frutas. 
A Companhia Força e Luz Cataguases Leopoldina (CFLCL), empresa responsável pela construção da referida UHE, iniciou as negociações com a população atingida em setembro de 1995, efetivando algumas negociações individuais, além de cooptação de lideranças locais, o que causou, inicialmente, uma desmobilização e fragmentação da população local. Em setembro de 1996, a empresa instalou placas nos terrenos adquiridos de alguns proprietários, comunicando que a referida área pertencia a ela; logo após, confeccionou um jornal informativo que foi divulgado na região, expondo a propaganda do futuro empreendimento. A partir dessas ações, a população, sem deter muito conhecimento de seus direitos e a quem recorrer, iniciou um processo de insatisfação compartilhada, o que serviu para emergir uma partícula inicial de uma ação coletiva.

Ao mesmo tempo, mesmo sem possuir as licenças prévias e de instalação, a empreendedora divulgou publicamente que as obras seriam iniciadas em outubro de 1996. Posteriormente, a empresa solicitou a licença prévia sem comunicar a população atingida sobre seu direito de requerer uma audiência pública, na qual os atingidos poderiam questionar o empreendimento e ponderar sobre as negociações. Após esse episódio, a Igreja e lideranças locais deram início à procura por orientação acerca da defesa de direitos, em que surgem as presenças do $\mathrm{NACAB}^{8}$ e da Comissão Pastoral da Terra (CPT) de Belo Horizonte, para assessorar as famílias atingidas.

De acordo com Rothman (2001), naquele mesmo ano, fora realizada uma reunião com um agente da CPT, dando início à criação de uma comissão local para realizar as negociações com a empresa, e também foram estabelecidos os primeiros contatos com a assessoria do NACAB.

Nos momentos seguintes, a assessoria apresentou duas formas de negociação que a comunidade poderia encontrar: a coletiva (fortemente reforçada pelos grupos de apoio) ou a individual. Além dessas formas de negociação, a assessoria indicou uma estratégia, que seria a de realizar uma ação civil pública, uma vez que a comunidade havia perdido o prazo para pedir a audiência pública. Contudo, nesse momento, alguns dos proprietários das maiores porções de terras já haviam negociado suas propriedades de forma individual e já não queriam mais participar do movimento, para fortalecê-lo.

8 O NACAB (Núcleo de Assistência às Comunidades Atingidas por Barragens) foi um projeto universitário de extensão que prestava assessoria às comunidades atingidas por barragens da região da Zona da Mata Mineira. A partir de 2001, foi criada uma ONG que também adotou o nome de NACAB, fazendo com que o projeto de extensão da UFV tivesse que mudar seu nome para PACAB (Projeto de Assessoria às Comunidades Atingidas por Barragens). 
De acordo com Rothman (2001), poucos optaram pela negociação em conjunto, o que fez com que a Igreja local, o NACAB e o Movimento dos Atingidos por Barragens regional (MAB-ARD) realizassem um trabalho de base, com o intuito de levar informações à população atingida, tanto sobre os possíveis impactos negativos que a construção da barragem poderia levar para suas vidas quanto com relação às formas de negociação que lhes seriam de direito. Apesar do esforço das entidades mediadoras, a população ainda se encontrava pouco mobilizada para a ação coletiva, talvez pela falta de informações precisas sobre o empreendimento, sobre seus direitos e também por causa dos conflitos locais acirrados pelos momentos de tensão e incerteza. Foi estranho compreender tal fato, mas a população se encontrava em uma situação de pouca mobilidade, de pouca união, em um contexto em que cada família pretendia resolver seu "problema" sozinha, e não em conjunto, como orientado pela Igreja e pelo NACAB. Inicialmente, acreditou-se que cada família queria negociar o valor de suas terras de modo individual, na tentativa de garantir melhores preços, porém não foi isso o que aconteceu, uma vez que os valores pagos foram muito aquém do valor de mercado das terras, naquela época.

Nesse contexto, as negociações foram realizadas de maneira individual, proposta realizada pela empresa, que ofereceu para adquirir as terras a serem alagadas, realocar as benfeitorias e, em alguns casos, permutas, ou seja, trocas, por outras terras ou imóvel na cidade mais próxima.

Com a construção dessa barragem, noventa e quatro famílias foram atingidas diretamente, das quais vinte e oito foram deslocadas para outras áreas rurais e urbanas e sessenta e seis famílias permaneceram no local, ainda que realocadas. Como se percebe, a grande maioria das famílias atingidas permaneceu no local, embora com modificações impostas pela construção da barragem, como o alagamento de terras férteis, de casas, da cachoeira local, do campo de futebol, etc.

\section{A CHEGADA DA BARRAGEM: "ELES INSISTEM DEMAIS, IGUAL FURÚNCULO NA GENTE"}

Um fato novo sempre gera diferentes formas de percepções e interpretações, de acordo com as experiências individuais e coletivas socialmente construídas.

No caso da notícia sobre a construção de uma barragem, sua divulgação chega entre aqueles que serão atingidos, fazendo com que comecem a processar as informações que nem sempre chegam de forma clara. Nesse processo, é comum o surgimento de diferentes pontos de questionamento. Mesmo não conhecendo todo o processo de licenciamento, negociações e construção de uma barragem, alguns 
atingidos poderão questionar a perda de suas propriedades e de suas formas de vida; outros poderão perceber o empreendimento como possibilidade de mudança positiva, seja em relação a um deslocamento para outro local, seja em relação a um novo padrão socioeconômico, advindo do valor recebido pela venda ou indenização de suas terras.

Para os jovens do meio rural, a construção de uma barragem pode representar novas possibilidades de vida, como a mudança para a cidade, a possibilidade de dar continuidade aos estudos, como apontado na pesquisa de Medeiros (2002, p. 15):

Os jovens rurais oscilam entre o projeto de construírem vidas mais individualizadas, o que expressa no desejo de "melhorarem o padrão de vida", de "serem algo na vida", e o compromisso com a família, que se confunde também com o sentimento de pertencimento à localidade de origem, já que a família é um "espaço privilegiado de sociabilidade".

Assim, as percepções das famílias atingidas sobre um projeto de barragem podem ser variadas. É nesse contexto que o presente estudo buscou captá-las e apreender o significado impresso ao empreendimento UHE Cachoeira do Emboque, pelos atingidos, após dez anos de sua construção.

Ao iniciar as entrevistas em campo, as primeiras impressões passadas pelas famílias, ao serem questionadas sobre o empreendimento e suas memórias sobre a época das negociações e implantação do projeto, revelam que muitos não acreditavam que um dia ele viria a se concretizar. De acordo com os entrevistados, as notícias sobre a construção da barragem já existiam há mais de trinta anos, criando-se, assim, uma imagem de que ela nunca viesse a se efetivar:

Já tinha uns trinta anos ou mais que veio um helicóptero uma vez com gente pra medir o local, falando que ia construir uma barragem. De tempo em tempo vinha gente aqui, mas nunca saía. Quando foi construir mesmo o pessoal da empresa veio medindo, colocando placa, indo nas casas das pessoas falando que ia construir (informante proprietário, 60 anos).

Como visto nos depoimentos, o fato de se realizarem estudos de viabilidade hidroenergética e nunca se concretizar o empreendimento levou a população a não acreditar na possibilidade de sua efetivação naquele momento. Contudo, em 1995, a CFLCL inicia o processo de pedido de licenciamento na FEAM, recebendo a licença prévia, documento que permite o pedido de licença de instalação, com o qual se 
tem a autorização para o início da construção da barragem. Nesse mesmo ano, a empreendedora iniciou algumas negociações individuais, adquirindo algumas propriedades e afixando placas no local, informando que a referida área pertencia à empresa, além de divulgar um jornal informando sobre o empreendimento que ali seria construído.

Vainer (2000) aponta, em seu trabalho, algumas táticas de desarticulação das comunidades, realizadas pelas empresas do setor energético, e uma delas foi realizada pela CFLCL, quando ela comprou parte das melhores terras locais para instalar seu canteiro de obras e demonstrar à população que o empreendimento era concreto e irremediável. De acordo com o depoimento coletado do representante local da comunidade de Granada, a compra das terras do maior proprietário local serviu para intimidar a comunidade e mostrar que, se a empresa pôde comprar terras do maior proprietário, poderia comprar a dos menores também.

A partir desses eventos e de acordo com a percepção dos atingidos, eles inferiram que o governo já havia liberado a construção da barragem, não podendo, então, a população, criticar ou tentar impedir a efetivação do empreendimento.

De acordo com o depoimento de um dos atingidos, representantes da empreendedora chegavam repentinamente com a notícia da compra das terras e os pressionavam a vendê-las rapidamente, sem oferecer tempo para que pudessem refletir sobre a questão ou mesmo para procurar informações sobre seus direitos.

\begin{abstract}
Ah, primeiro falaram que nóis ia ter emprego, casa nova, aí eu fiquei animado, achei que ia arresorver minha vida. Mas depois começou um tal de Paulo ir nas casa das pessoa pressionar e forçar a negociar, tratava mal a gente, dizia que ia mandar alagar tudo com nóis aqui. Aí nóis começô a percebê que o negócio era outro, tava ficando feio... [...] Ah, como sempre cada um quer uma coisa. Eu queria o que era meu, não queria sair e deixar minhas coisa. Mas falaram que iam alagar e que se eu não assinasse o papel não ia receber nada no final. Acabei aceitando o que eles disseram que eu tinha que ganhar, não deu pra nada, fiquei na pior, o dinheiro durou poucos meses (informante proprietário, 57 anos) ${ }^{9}$.
\end{abstract}

Como pode ser observado, essa “chegada do estranho” à comunidade, representado pela chegada da barragem, como citado por Martins (1993), pode geralmente acontecer de maneira persuasiva, com um discurso sedutor que propõe a uma população fragilizada pelo momento a vinda de progresso, desenvolvimento, oferta

9 Depoimento gravado com a permissão do informante. 
de emprego, dinheiro, oportunidade de concretizar o sonho de ir para a cidade, etc. Para aqueles que veem na barragem a possibilidade de ganhos e prosperidade, o discurso chega com facilidade a esses interlocutores e pode se tornar efetivo.

Aquelas famílias que já possuíam a intenção de sair do local ou se interessaram pela possibilidade de mudanças negociaram suas terras em 1995 de maneira individual com a empreendedora. Os demais se mobilizaram para criar uma comissão local a fim de realizar as negociações de maneira coletiva, porém, por falta de informações sobre o empreendimento e seus direitos enquanto atingidos, perderam o prazo para pedir uma audiência pública, espaço institucional em que poderiam criticar o empreendimento.

De acordo com dados obtidos pelos depoimentos coletados em entrevistas nesse período, alguns atingidos afirmavam que: "o que a empresa quer é ficar livre do pessoal o mais logo" (Rothman; VIEIRA, 1997, p. 17). E essa declaração confirma o que foi dito por Martins (Rothman; VieIRA, 1997, p. 61-63), o qual afirma que tais projetos têm como pressuposto a remoção dessas famílias, também consideradas, segundo Vainer e Araújo (1992), como enclaves ou problemas para a empresa, a serem removidos do local para a viabilização do empreendimento:

A região, o meio ambiente e tudo o mais são olhados a partir do grande projeto, parte em função de uma estratégia setorial. Quanto às populações, passam a ser um obstáculo que deve ser removido para limpar o terreno (VAINER; ARAÚJO, 1992, p. 20).

Ainda nesse mesmo ano, a comissão local pediu auxilio às entidades mediadoras (NACAB, CPT e MAB) para que pudessem ser mais bem orientados durante o processo de negociações com a empresa. A negociação coletiva é fortemente reforçada nesse momento pelas assessorias, porém ainda existiam conflitos de interesses que desarticulavam o processo. Um atingido comenta sobre as negociações coletivas: "A união tá difícil, ou vende todo mundo ou não vende ninguém" (Rothman; Vieira, 1997, p. 21).

Como a empresa já estava presente no local, realizando um trabalho de aproximação e convencimento com a comunidade, foi mais fácil para o empreendedor desarticular a população e convencê-la de que as negociações individuais seriam mais interessantes. Tais momentos foram apresentados anteriormente por Vainer e Araújo (1992, p. 20), quando relatam sobre as estratégias adotadas pelo setor elétrico para a desarticulação das populações atingidas, sejam elas: "desinformação, estratégia territorial patrimonialista e negociação individual”. 
Ainda de acordo com Rothman e Vieira (1997), poucas informações foram enviadas pela empreendedora à população, que não possuía maiores conhecimentos no que se referia às indenizações, à venda ou à permuta de terras, direitos dos atingidos e de quem se enquadrava nessa categoria.

Também havia um grupo que afirmou acreditar na idoneidade da empresa, considerando que ela faria o melhor pela população. $\mathrm{O}$ argumento utilizado por esses atingidos, conforme sugerido pela empreendedora, era o de que ela iria construir outras barragens e deveria realizar boas negociações com o presente empreendimento, como forma de servir de exemplo para as futuras barragens que pretendiam construir na região.

Dessa forma, por encontrarem-se desarticulados, os atingidos afirmam ter acatado as orientações do empreendedor que, segundo eles, os instruiu para a negociação individual, convencendo-os de que, se esta fosse realizada de maneira coletiva, acabaria prejudicando as famílias, pois cada caso seria diferente um do outro.

O resultado é que se observam declarações como:

Se a pessoa der sorte e saber negociar direito, sai mais beneficiada que em negociação coletiva...

Não fui mais nas reuniões porque tem que negociar é com a empresa, tem que pagar as pessoas mesmo, então não é necessário negociar junto... (depoimentos citados em Rothman; Vieira, 1997, p. 21).

Observa-se, nessas declarações, a possível falta de articulação e orientação sobre o processo de negociações. Além disso, a falta de informações precisas sobre seus direitos parece ter causado muitas dúvidas aos não proprietários (meeiros e empregados).

Se der fico, se não der, já estou acostumado a mudar de casa.

Para quem não tem terra é difícil negociar com a empresa.

Nós temos um empregado, mas a negociação deles tem que ser com a empresa, pois são eles que tão querendo tirá-los de lá, não nós (depoimentos citados em RothMAN; VIEIRA, 1997, p. 21).

Pode-se aqui notar que esses atingidos pareciam não possuir conhecimentos sobre seus direitos, fazendo com que alguns acreditassem não os possuir perante a implementação do projeto, conformando-se, inclusive, em sair do local. Outro 
aspecto importante a ser observado refere-se à indiferença entre a possibilidade ou não de mudança, aludindo questões sobre o sentimento de pertencimento ou até mesmo de conformismo perante a situação de sua posição social, muitas vezes desvantajosa, uma vez que, por serem meeiros, aquelas pessoas se consideravam sem território, tanto físico quanto pelo sentimento de pertencimento ao local, sem lugar definido no espaço. O fato de não ser proprietário afetou profundamente as interpretações e formas de negociação das terras.

Essa desarticulação local também contou com outro episódio relevante, como relatam os próprios atingidos:

À custa de dinheiro a pessoa acaba por isso. Aquelas pessoas traíram a gente por dinheiro e perderam tudo. No fim essas pessoas foram compradas, receberam terra e dinheiro e prejudicaram todos. As pessoas que a gente confiou, letradas, iam em BH resolver tudo para todos, mas não fizeram nada. Foram comprados e muito agredidos psicologicamente. $\mathrm{O}$ nome da gente tem valor, não dá pra se vender (informante proprietária, 65 anos).

Tava tudo organizado, mas acabou. A empresa comprou os dois mais ricos e os pobres ficaram com nada. Perto de negociar, os representantes saíram e as pessoas ficaram sem saber o que fazer, sobraram e foram levados à Justiça para aceitarem o pouco dinheiro, se não seriam expulsos da terra. Pagaram mixaria, venderam por menos do que valia. Negociaram os ricos primeiro e os pobres foram obrigados a sair (informante proprietário, 48 anos).

Pode-se notar, então, por meio dessas palavras, que houve a percepção, por parte dos atingidos, da cooptação dos representantes da associação local, sendo este mais um fator que levou à desunião da comunidade, provocando insatisfação no resultado das negociações.

Dessa forma, a partir dessa desmobilização entre a população, redes de solidariedade, cooptação dos representantes da comissão local, bem como a presença de interesses incomuns acirrados pelo momento, a comissão acabou se desmantelando, fazendo com que as negociações acabassem ocorrendo de maneira individual.

Alguns atingidos relatam suas percepções acerca dessas negociações, nas palavras transcritas a seguir:

Ah, negociei do jeito deles. Eles fazia pressão e tinha que negociar logo senão iam alagar tudo e eu ia ficar no prejuízo (informante filho de proprietário, 36 anos). 
A gente tinha reunião, o padre falava pra unir e negociar junto, recebia informação da empresa também, mas foi tudo meio assim, a gente não sabia como fazer direito, os pessoal da empresa vinha e fazia medo, a gente acabava aceitando o que eles falavam com medo de ficar sem nada depois (informante proprietária, 68 anos).

A gente queria melhorar um pouco. Eles dariam quatro mil reais ( $\mathrm{R} \$ 4.000,00)$ pelas áreas atingidas ou nada. "Se não quiser, pode ir no Fórum buscar, que vocês não vão ganhar quase nada." Foi muita pressão. O resto daqui pra cima foi tocado pra lá. Colocaram luz na casa em troca do terreno perdido. Eles insistem demais fazendo raiva na gente, igual furúnculo na gente. Falaram até que eu tava com depressão só pra me mandar pra cidade. Mas eu não quis porque sou deficiente visual e ia acabar entrando em casa errada e levar porretada. Já sabia que a gente ia ficar prejudicado (informante posseiro, 68 anos).

Ao analisar os relatos, na fala do primeiro informante, é possível entender sobre o medo da população com relação ao poder político e econômico da empresa, que poderia concretizar suas ameaças e alagar a região com as famílias dentro de suas casas.

Já as palavras seguintes mostram o sentimento daquelas pessoas em relação à atuação da empresa, quando afirmam: "eles insistem demais fazendo raiva na gente, igual furúnculo na gente”. A insistência por parte da empresa é tão grande que chega a desgastar as pessoas, a ferir, igual a um furúnculo (doença de pele que causa pus e corrói o tecido em que está infectado).

A tensão criada sobre os atingidos chegou ao extremo quando outro deles acabou se suicidando no quintal de sua antiga residência.

Tinha muito parente e amigo aqui perto. Agora acabou tudo, até perdi um irmão por causa da barragem, ele se enforcou no quintal de casa porque arrependeu do negócio que fez com a empresa (informante proprietário, 66 anos).

A maior perda foi o tio. Ele ficou triste, não queria sair de lá, mas foi pressionado e entrou em depressão. Um dia, amanheceu enforcado. Antes de mudar falou que ia morrer lá (informante filho de proprietário, 30 anos).

Tal fato parece ter criado um grande pesar na população, principalmente nos parentes dessa pessoa, pois sempre relatavam o caso com muita tristeza. Todos 
os parentes que prestaram depoimento para a presente pesquisa não deixaram de tocar no assunto.

Assim, após concretizadas as negociações com as famílias atingidas pela UHE do Emboque, iniciou-se a realocação das que continuaram no local, para que a empresa pudesse liberar as terras que seriam alagadas para dar formação à represa.

A região onde se encontra a barragem é caracterizada por um relevo típico da região da Zona da Mata, sendo ele acidentado, isto é, com predomínio de colinas e vales estreitos.

Dessa forma, muitas casas da região do Emboque se encontravam na parte mais baixa do local, acompanhando o leito do rio, onde também se encontravam as áreas mais férteis para a agricultura. No entanto, para se criar um reservatório para uma barragem, a área no entorno do rio é alagada, o que fez inundar as casas e produções agrícolas ali presentes. Como a maior parte das propriedades começava na parte baixa próxima ao leito do rio e terminava nos topos de morro, as partes baixas das propriedades foram inundadas, e essas áreas foram indenizadas.

Nos arquivos pessoais das famílias pesquisadas, existem fotografias que mostram as casas nas quais habitavam antes da construção da barragem, como visto a seguir.

Como pode ser observado nas imagens, é possível visualizar alguns exemplos de antigas casas típicas da região, com características que remetem ao passado. No lugar delas, foram construídas novas casas nas partes mais elevadas de seus terrenos. Dessa forma, várias famílias vivenciaram essa perda, que reflete em dimensões imensuráveis para elas. Elas receberam novas casas ou as construíram com recursos da indenização recebida, que, na maioria dos casos, eram escassos ou insuficientes para tal.

As casas visualizadas, quando comparadas com as moradias anteriores daquela região, evidenciam a diferença espacial, uma vez que as atuais foram construídas em padrões diferentes, o que representou em uma perda de características passadas. Contudo, tal fato também não deixa de representar traços da "modernidade" inevitável chegando à região, como afirmado pela empresa proponente da barragem.

Aliada à perda da casa, também houve a perda de totalidade ou quase totalidade das terras, onde as partes mais férteis e agricultáveis, próximas ao leito do rio, "perderam-se" para dar lugar à represa, restando somente as partes mais altas das propriedades, que, por sua vez, não são próprias para a agricultura de várzea, principalmente para o cultivo de arroz, cultura que era presente em várias propriedades. Outras culturas também eram características da região e declaradas na entrevista realizada para a presente pesquisa, como milho, feijão, café e cana- 

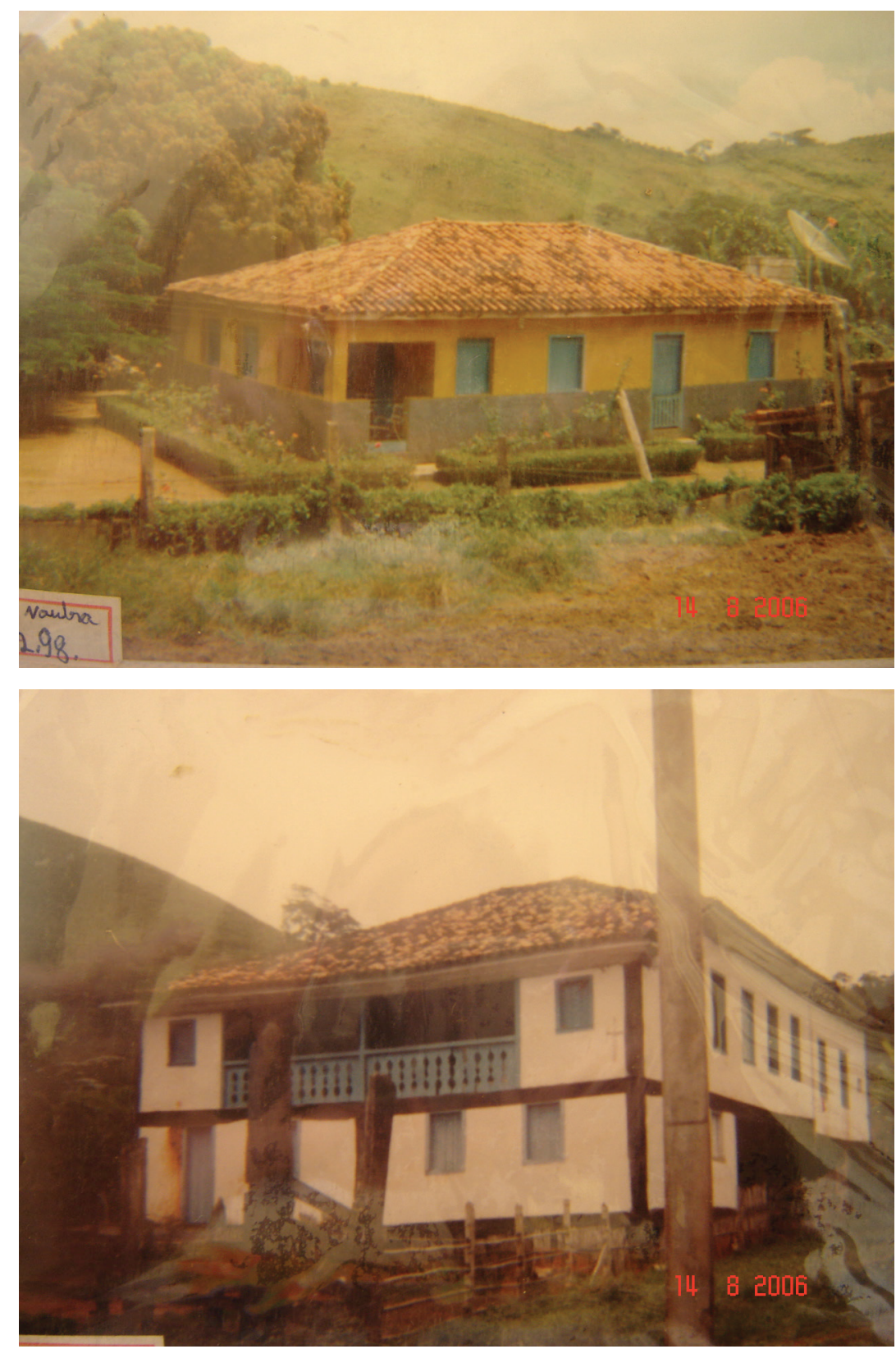

Figura 4. Fotos de casas antigas que existiam antes da construção da barragem, na região do Emboque. Fonte: arquivos pessoais de um dos atingidos.

-de-açúcar. O pomar também foi caracterizado como presente em praticamente todas as propriedades, para consumo da família.

A perda de terras ou de parte delas se reflete na nova estrutura fundiária local, ou seja, as vinte e oito propriedades declaradas apresentam áreas entre o e 10 ha, sendo que, na pesquisa realizada pelo Rima, em 1995, esse número era de dezoito propriedades. Com a venda de parte das propriedades para que se formasse o reservatório da barragem, as parcelas territoriais diminuíram, o que também 

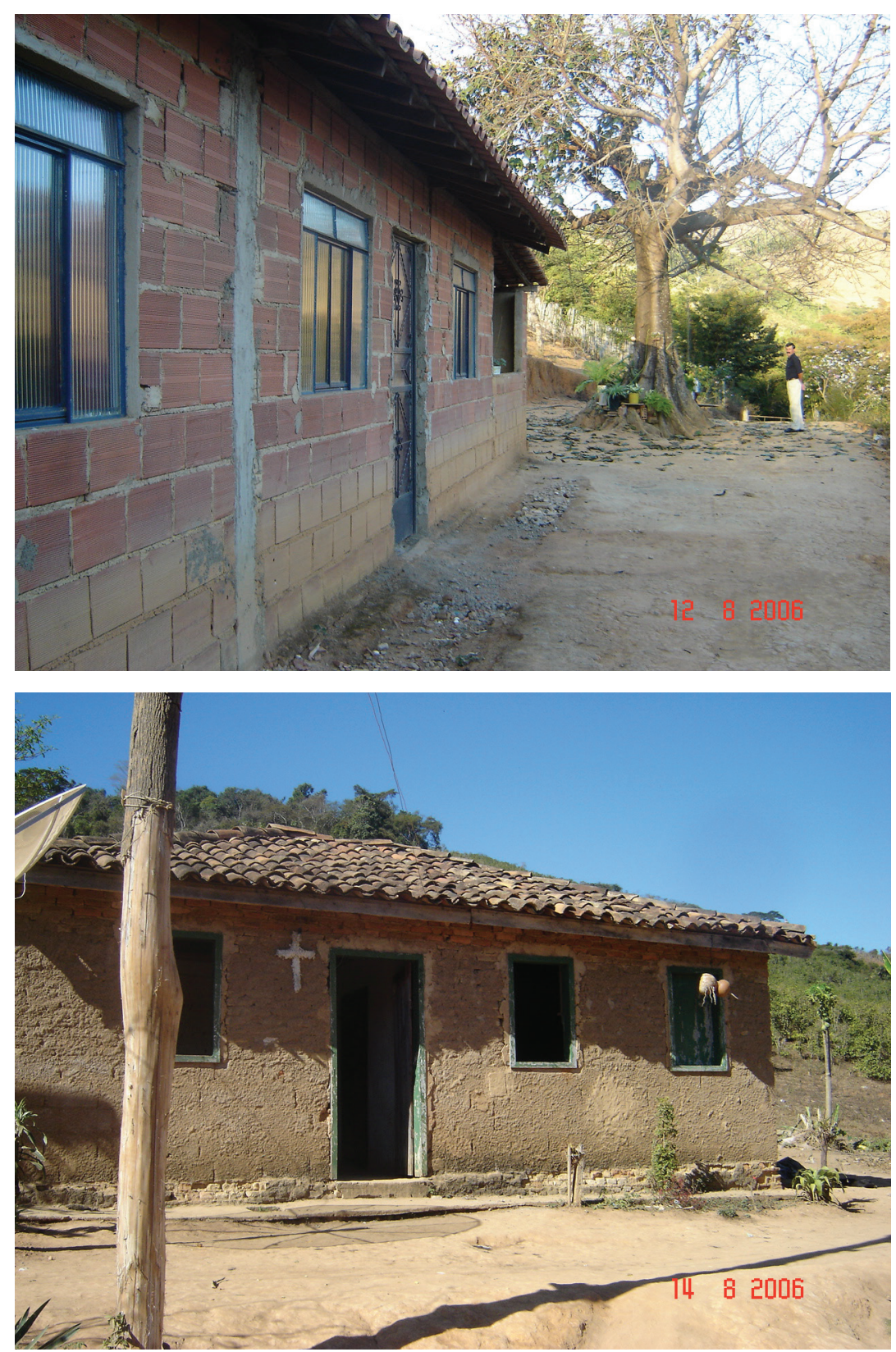

Figura 5. Foto das novas casas construídas pelos atingidos com recursos da indenização. Fonte: material produzido na pesquisa.

se reflete na diminuição da produção e da condição econômica das famílias. As maiores propriedades, encontradas em 1995, já não existem mais no local, uma vez que foram vendidas para a empreendedora.

Dessa forma, os meios e modos de vida dessas famílias foram alterados pela construção da barragem. Pelo fato de terem sido reduzidas as áreas de terras, os cultivos consequentemente diminuíram, bem como os tipos de cultivares e a 
forma como se relacionavam com a terra também se modificaram, ou seja, muitos daqueles que antes eram proprietários das terras passaram a ser meeiros ou arrendatários.

Pelo fato de terem sido reduzidas as áreas de terras, os cultivos daquelas culturas acabaram ou se tornaram quase inexistentes, fazendo com que a comunidade passasse a ter que consumir produtos vendidos no mercado, em vez de retirá-lo da terra, transformando a economia local.

Os relatos a seguir evidenciam melhor essa situação:

A gente vivia da agricultura, plantava tudo para consumir e vender, agora não tem onde plantar. Nós tinha era brejo pra plantar arroz, era bom por demais, trazia nosso sustento, agora acabou tudo (informante proprietário, 48 anos).

Antes eu tinha feijão, feijão e pomar para tirar as frutas para as crianças e pra gente comer em casa, mas o feijão era pra vender, vender e comer. Agora compro as coisas no mercado, tem que ir na cidade ou na venda em Granada pra comprar (informante proprietário, 52 anos).

Como se pode perceber nos relatos apresentados, as modificações em seus meios de vida causaram fortes efeitos na economia e na forma de alimentação da comunidade, uma vez que, antes, consumiam produtos retirados da propriedade e, atualmente, passam a ter que comprá-los nos supermercados da cidade próxima ou, até mesmo, a nem consumi-los por falta de condições financeiras para tal.

Já para outras famílias, de acordo com suas percepções, parece que a realidade foi outra:

Mudou muita coisa pra gente, agora somos meeiros, estamos mexendo com arroz. Perdemos a casa e o emprego (informante proprietário, meeiro, 37 anos).

Estamos na agricultura, somos meeiros, agora não temos como plantar, porque só temos a casa (informante proprietário, meeiro, 48 anos).

A gente planta pouco com os outros porque não temos condições de organizar a propriedade. Trabalho também como autônomo, o que encontrar, não tenho trabalho fixo (informante proprietário, 52 anos). 
Como se percebe nos relatos apresentados, algumas famílias acabaram tendo que "optar" pelo trabalho assalariado temporário, pelo trabalho à meia ou por serem autônomas, uma vez que afirmam ter perdido a condição de proprietárias rurais e não possuem outras alternativas econômicas, a não ser essas, configurando mudanças na estrutura e condições de trabalho das famílias, ao perderem suas terras agricultáveis para dar lugar à barragem.

Além disso, anteriormente à construção da represa, existia uma ponte que ligava os dois lados do rio, diminuindo a distância entre os moradores e a cidade, e, ao alagar a antiga ponte, a comunidade se distanciou ainda mais, além de alguns laços de amizade e vizinhança serem distanciados, uma vez que não foi construída outra ponte ou oferecida outra forma de acesso ao outro lado da margem, para dar novo acesso aos locais.

Essas mudanças na paisagem local são percebidas pelos atingidos da seguinte forma:

Bom, agora a gente tem que andar muito pra ir pra cidade, a estrada ficou grande e perigosa. Isso afasta a gente das pessoas e dificulta a vida, se um passa mal a gente nem tem como correr pra cidade (informante proprietário, 53 anos).

Aqui precisava de ponte porque agora tem que dar volta grande pra ir pra cidade. Quem ficou do outro lado ficou perdido (informante filho de proprietário, 30 anos).

Como se pode perceber pelas palavras dos entrevistados, a falta da ponte, uma das formas de interligação das pessoas da comunidade, é percebida por eles como algo que os "afasta das pessoas" e os faz se sentirem "perdidos". Dessa forma, parte da comunicação ali se perdeu, bem como aqueles velhos laços sociais que existem entre famílias vizinhas, diminuindo os encontros, as conversas da janela, a simples troca de alimentos ou de favores, ou seja, a vida cotidiana foi transformada. Essa imposição de um outro estilo ou forma de vida à comunidade, fruto de uma visão totalmente técnica e economista, além de cometer injustiça social, não deixa de ser uma injustiça ambiental (Martinez-Alier, 1999; AcSERAld et al., 2004), uma vez que não atende ao contexto sociocultural no qual se insere, desigualmente, o ônus da produção de energia elétrica.

Além dessas alterações nos meios e modos de vida das pessoas, outra questão sentida e percebida pelas famílias atingidas é o efeito psicoemocional que as modificações impostas pelo empreendimento geram nessas pessoas. 
Nas palavras a seguir pode-se perceber como essas e outras questões são notadas e sentidas pela população:

Nasci e fui criada aqui. Tinha dia que chorava só de pensar que iriam alagar as árvores do local. [Ela se emociona e chora ao iniciar a conversa] Não gosto de falar nisso, é muito triste. O marido não gosta e nem deixa eu falar nisso. Você lembra da estrada desde que nasce, ia pra escola a pé, e ver a estrada sumir e tudo sumir... (informante meeira, 65 anos).

Na questão das barragens, o que mais machuca é o psicológico. Perdemos as cachoeiras, o futebol e a família, tudo isso deixou saudade (informante proprietário, 60 anos).

[...] as lembrança não se fecham e as feridas doem muito (informante proprietária, 45 anos).

Os relatos apresentados mostram como a cachoeira, o campo de futebol e cada lugar perdido deixam saudades e remetem às boas lembranças vivenciadas no local.

Para quem saiu da região, além de ter sido fisicamente desterritorializado, teve que, por conseguinte, refazer relações sociais no novo local em que foi inserido, isso sem contar com o contato familiar que foi distanciado.

Antes a gente morava aqui em Bicuíba. A terra era nossa e foi indenizada, perdemos a casa e o emprego, agora somos meeiros porque o pouco que recebemos não deu pra comprar terra, só nossa casa. Fomos pra Caputira, não gosto do lugar que vivemos, foi depois dessa mudança que apareceu minha epilepsia, foi por causa dessa barragem que fiquei doente (informante filha de antigos proprietários, 18 anos).

De acordo com as palavras da informante, percebe-se como as mudanças nas relações de trabalho fazem com que os proprietários percam sua autonomia nesse contexto. Antes eram os proprietários de sua terra e donos de sua produção, agora afirmam ter se tornado empregados ou ter que dividir a produção em terras que não são mais deles. A relação entre a terra e o trabalho passa a coexistir de maneira diferente e "estranha" para a comunidade. Aqueles que antes eram proprietários e 
donos de suas terras e produções agrícolas agora têm que produzir em terra alheia, dividindo os custos e os lucros de sua produção.

Aliado a essas questões, no decorrer das entrevistas, percebe-se que alguns espaços que eram considerados lugares carregados de simbologia, por ser palco para os encontros sociais, lazer e divertimento da população, também se perderam para que a barragem pudesse ser construída. Exemplo disso é a cachoeira que ficou submersa, mencionada várias vezes pelos moradores com muita emoção e saudosismo.

Antes a gente tinha a cachoeira, o areião. Agora só água parada com pernilongo e sujeira. Tinha área de lazer na cachoeira, o pessoal brincava, era uma delícia, bonito, sadio. Nasci aqui. Sempre ouvi o barulho da cachoeira, agora nada (informante proprietária, 42 anos).

Desanimaram as coisas por aqui, até as festas diminuíram, o pessoal desanimou. Quando tinha a cachoeira era bom, todo mundo ia se encontrar lá, as crianças, adulto, reunia tudo. Agora não tem como, só se for na casa do amigo, mas tomar banho, pescar, nunca mais (informante filha de proprietário, 40 anos).

É importante considerar que um atributo da paisagem, a cachoeira, perdeu-se e, junto com ela, um símbolo de relações sociais. Assim, a construção da praça não se apresenta alternativa de lazer, nem tampouco espaço de referência para os moradores, que não consideram ali um lugar de vivência.

Dentro dessa perspectiva, a desterritorialização também leva à exclusão social, uma vez que, ao perder em parte de bens materiais e simbólicos, o atingido e em sua família também perdem algumas formas de participação na sociedade, seja de natureza econômica, seja de natureza social (MARTINEz-Alier, 1999).

Por conseguinte, os atingidos, deslocados compulsoriamente, reassentados e/ou realocados no entorno do lago, defrontam-se com outros desafios, pois a chegada ou o rearranjo no outro lugar representa, para eles, (re)fazer e (re)construir relações sociais e econômicas.

\section{CONSIDERAÇÕES FINAIS}

Como se pode notar, a barragem possui diferentes representações. Nos relatos aqui apresentados, percebe-se que os atingidos possuem interpretações com conotações diferentes, sejam elas boas, sejam ruins. Muitas delas abordam 
sobre a desunião, a morte, a destruição. Já pelo relato de outras famílias, existe a percepção de que a barragem não representou muitas diferenças em seus meios e modos de vida, trazendo até outras possibilidades futuras, para aqueles que já estavam cansados da vida no meio rural e precisavam apenas de um "motivo" ou "incentivo" para mudar suas vidas e ir para a cidade. Para outros, a vida entre o rural e o urbano já era cotidiana, pois alguns já possuíam casas na cidade ou filhos que estudavam ou trabalhavam no local, motivo esse que já arraigava neles certa vontade de se mudarem para a cidade, para ficarem perto de suas famílias.

A presença de um empreendimento como uma barragem traz muitas implicações em diversos âmbitos, fato consumado pela literatura e pela realidade empírica. Dependendo da realidade de cada atingido, essas implicações terão proporções e conotações diferentes. No entanto, sabe-se que as implicações negativas são as mais constatadas, pois trazem para as famílias atingidas algumas perdas por elas consideradas irreparáveis, como se pôde observar por meio dos relatos apresentados, em que houve a perda das casas, das produções rurais, das condições de vida, dos laços de amizade e de parentesco e toda a vida ali vivida e planejada se acabou em questão de momentos, ao se formar a represa, trazendo consigo angústia e insatisfação por parte de quem vive diretamente e indiretamente esse drama.

Além disso, ao serem questionados sobre o processo de deslocamento e realocação das famílias, apontam a insatisfação inicial com relação às negociações, afirmando não terem ficado satisfeitos com os valores recebidos nas indenizações. Como a maior parte das propriedades possuía áreas próximas ao leito do rio e áreas em topos de morro, elas permaneceram intactas e foram utilizadas para a construção de novas casas, uma vez que as que ficavam perto do rio foram alagadas. Ao terem que construir novas casas no topo dos terrenos, os atingidos também relatam insatisfação com relação às construções, à falta de verba suficiente para construí-las, mostrando forte sentimento de perda em relação às casas antigas onde, muitas vezes, nasceram seus filhos, pais e até avós.

Outras informações captadas por essa população são que, em sua maioria, a comunidade formava-se, antes da construção da barragem, por pequenos produtores rurais que se alicerçavam no trabalho familiar. A partir de suas percepções, foi possível obter informações sobre suas atividades econômicas, relação com a terra (propriedade, posse ou meeiros), tipos de produção rural, estrutura fundiária, no passado e nos dias atuais. Os dados construídos informaram que o tamanho de pequenas parcelas territoriais, já existentes antes da construção da barragem, diminuiu ainda mais, em razão da perda de partes dos terrenos utilizados para a formação da represa. Assim, aumentou o número de pequenas propriedades no 
local. Tal fato também alterou a caracterização das produções agrícolas da região que, anteriormente, eram voltadas para o comércio e a subsistência e, nos dias atuais, estão voltadas apenas para o autoconsumo. Essa modificação também alterou os hábitos alimentares da população, pois passou a ter que consumir alguns produtos industrializados e comprados em mercados nas cidades ou nos distritos mais próximos.

Porém, como existem diversidades de percepções sobre os efeitos do empreendimento, outras famílias se afirmaram satisfeitas, uma vez que parece não terem sentido muitas alterações ou perdas em seus meios e modos de vida. Alguns até afirmam ter melhorado as condições de suas vidas.

Os significados da barragem podem ser diversos, e sua interpretação depende da experiência de vida de cada pessoa, de sua história com o lugar, sua identificação, bem como da capacidade ou não de se adaptar às adversidades.

Dessa forma, ao desvendar as especificidades do caso Emboque, acredita-se que o presente trabalho, longe de encerrar ou esgotar o assunto, possa auxiliar na compreensão e reflexão sobre os efeitos advindos da construção das hidrelétricas, que causam as mais variadas perdas nas comunidades atingidas, mas também procura conscientizar as populações atingidas por barragens e a sociedade em geral, com o maior número de informações possível, sobre os projetos das hidrelétricas e suas consequências. Finaliza-se o estudo concordando com as palavras de Tuan (1983), que reflete sobre o direito e a necessidade do homem de ser, estar e pertencer a um lugar, símbolo de sua liberdade, humanização, ação, valores estabelecidos e significados construídos de forma coletiva. Por todas essas representações, Tuan (1983, p. 61) afirma que "os seres humanos necessitam de espaço e de lugar”, espaços esses que precisam ser respeitados e vistos sob outras formas pelo setor elétrico, bem como pelos órgãos ambientais e governamentais.

Essa reflexão sobre os resultados negativos de tais empreendimentos pode levar à elaboração de novas políticas públicas que possam reavaliar todo o processo de licenciamento e buscar alternativas na legislação para que as implicações dos efeitos negativos, tanto no meio ambiente como na população, sejam evitadas. Também se entende que a busca por outras fontes energéticas menos prejudiciais ao homem deva ser priorizada pelos governantes, ainda que em detrimento dos interesses particulares das empresas que se envolvem no complexo processo de construção de usinas hidrelétricas. 


\section{REFERÊNCIAS BIBLIOGRÁFICAS}

ACserald et al. Justiça ambiental e cidadania. Rio de Janeiro: Relume Dumará, 2004. p. 23-39.

Carvalho, O. A. Migrações compulsórias, territorialidade e lugar na implantação de hidrelétricas na bacia hidrográfica do rio Uruguai. In: Encontro CiÊNCIAS SociaIs E BARRAgENS, 1. 2005, Rio de Janeiro. Anais... 1 CD-ROM. Rio de Janeiro, 2005.

CERnea, M.; MCDOwell, C. Risks and reconstruction: experiences of resettles and refugees. Washington D.C.: The World Bank, 2000.

Ludwig, M. P. Descortinando a paisagem - a construção social do espaço e o sentido de lugar: uma comunidade rural da Zona da Mata de Minas Gerais nos umbrais do século XXI. 239 f. 2003. Tese (Doutorado em Estruturas Ambientais Urbanas) Universidade de São Paulo, São Paulo, 2003.

Martinez-Alier, J. Justiça ambiental (local e global) In: Cavalcantı, Clóvis (Org.) Meio ambiente, desenvolvimento sustentável e poíticas públicas. Cortez: São Paulo, 1999. Martins, J. de S. A chegada do estranho. São Paulo: Hutitec, 1993.

Medeiros, J. C. Juventude e modernidade em Casa Nova: reflexões a propósito de um projeto de barragem em Minas Gerais. 133 f. 2002. Dissertação (Mestrado em Extensão Rural) - Universidade Federal de Viçosa, Viçosa, 2002.

Minayo, M. C. (Org.). Pesquisa social: teoria, método e criatividade. Petrópolis: Vozes, 1997. Rothman, F. D. A emergência do movimento dos atingidos pelas barragens da bacia do rio Uruguai 1979-1983. In: Navarro, Z. N. (Org.) Política, protesto e cidadania no campo: as lutas sociais dos colonos e trabalhadores rurais no Rio Grande do Sul. Porto Alegre: UFRGS, 1996.

A comparative study of dam-resistance campaigns and environmental policy in Brazil. Journal of Environmental \& Development, v. 1, n. 4, p. 317-344, Dec. 2001.

Rothman, F. D.; Vieira, A. J. F. A privatização do setor elétrico e os impactos sócioculturais e ambientais da construção de barragens na bacia do Alto Rio Doce de Minas Gerais. 31 p. 1997. Relatório final de pesquisa, bolsa de iniciação científica do CNPq - Universidade Federal de Viçosa, Viçosa, 1997.

SAntos, M. A natureza do espaço. São Paulo: Edusp, 2002.

Scherer-Warren, I.; Reis, M. J.; Bloemer, N. M. Alto Uruguai: migração forçada e reatualização da identidade camponesa. Travessia Revista do Migrante, ano 2, n. 6, p. 29-33, jan./abr. 1990.

SigAud, L. M. Implicações políticas e sociais de grandes projetos hidrelétricos sobre as populações indígenas e camponesas. Série Ciências Ambientais - USP, Instituto de Estudos Avançados Coleção Documentos, n. 16, mar. 1994. 
Tuan, Yi-Fu. Espaço e lugar: a perspectiva da experiência. São Paulo: Difel, 1983.

VAINER, C. Águas para vida. Jornal do Brasil, de 4 de abril de 2000.

VAINer, C. B.; Araujo, F. G. B. Grandes projetos hidrelétricos e desenvolvimento regional. Rio de Janeiro: CEDI, 1992.

Recebido para publicação em 19/03/13. Aceito para publicação em 06/o8/13. 